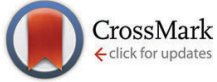

Cite this: Phys. Chem. Chem. Phys., 2016, 18, 25058

Received 13th June 2016

Accepted 8th August 2016

DOI: $10.1039 / c 6 c p 04100 k$

www.rsc.org/pccp

\title{
Calculation of Raman parameters of real-size zigzag $(n, 0)$ single-walled carbon nanotubes using finite-size models $\dagger$
}

\author{
Teobald Kupka, ${ }^{a}{ }^{a}$ Michal Stachów, ${ }^{a}$ Leszek Stobiński $^{b}$ and Jakub Kaminský*c
}

Structural and selected Raman features of pristine single-walled carbon nanotubes (SWCTNs) with diameters from 0.4 to $1.2 \mathrm{~nm}$ and total lengths up to $2.15 \mathrm{~nm}$ were studied using the density functional theory (DFT) at the UB3LYP/6-31G* level. Models of different lengths (1, 4, 6 and 10 adjacent bamboounits) of zigzag $(n, 0)$ SWCNTs, for $n$ ranging from 5 to 15 , were studied. Highly systematic changes of individual CC bond lengths and angles along the nanotube axis were observed and described for the longest models. Predicted Raman active radial breathing mode (RBM) vibrational frequencies regularly decreased upon increasing the nanotube diameter and only a negligible effect of the tube length was observed. The changes in calculated RBM frequencies with increasing diameter were close to values estimated using empirical formulas. The experimental G-mode characteristics were reasonably well reproduced using the 4-unit model, especially for tubes with the diameter $d>1 \mathrm{~nm}$. Raman features were also determined for cyclacenes representing the shortest models of SWCNTs. Calculated RBM frequencies of cyclacenes match closely the values for longer SWCNT models but are too inaccurate in the case of the G-mode. For the first time, the Raman properties of SWCNTs were also determined using the Cartesian coordinate tensor (CCT) transfer technique, thus providing reasonable frequencies of Raman active bands for long tubes consisting of 10 bamboo-units.

\section{Introduction}

Carbon nanotubes $^{1-5}$ together with fullerenes ${ }^{6}$ and graphene, ${ }^{7}$ new allotropes of ordered carbon, have attracted enormous attention ${ }^{1,2,6}$ causing a "golden rush" in nanotechnology. ${ }^{4}$ One of the most important structural parameters characterizing carbon nanotubes is their diameter typically ranging from $\sim 0.3$ to tens of nanometers. ${ }^{4,8-18}$ Apart from SWCNTs stabilized by confinement, no freestanding ultranarrow carbon tubes have been observed so far. ${ }^{8,15,17,19-22}$ Besides standard SWCNTs, pristine, as well as functionalized carbon nanotubes, is produced nowadays representing thus integral parts of basic research or industrial applications. ${ }^{423-25}$ Single-walled carbon nanotubes of different diameters are able to hold various small molecules in their inner space and could thus serve as pots for chemical reactions

\footnotetext{
${ }^{a}$ University of Opole, Faculty of Chemistry, 48, Oleska Street, 45-052 Opole, Poland. E-mail: teobaldk@gmail.com

${ }^{b}$ Faculty of Chemical and Process Engineering, Warsaw University of Technology, 1, Waryńskiego Street, 00-645 Warsaw, Poland

${ }^{c}$ Institute of Organic Chemistry and Biochemistry AS CR, Flemingovo nam. 2, 166 10 Prague, Czech Republic. E-mail: kaminsky@uochb.cas.cz

$\dagger$ Electronic supplementary information (ESI) available: Structural and electronic data (tables and figures), relative energy distributions, and comparison of Raman features calculated using different approaches. See DOI: 10.1039/c6cp04100k
}

in very small dimensions ${ }^{25}$ or as reservoirs for encapsulated small molecules. ${ }^{26-30}$

The energy gap $E_{\mathrm{g}}$ (in $\mathrm{eV}$ ) between the highest occupied molecular orbital (HOMO) and the lowest unoccupied molecular orbital (LUMO) is important in terms of potential practical applications of carbon nanomaterials. ${ }^{31,32}$ For example, the electrical conductivity of SWCNTs is related to their $E_{\mathrm{g}}$, diameter and chirality. ${ }^{4}$ Originally, $(n, m)$ tubes with $\lambda=\bmod (n-m, 3)=0$ were considered as metallic, ${ }^{33}$ however, due to the curvature effects and s-p hybridization in extremely small-diameter SWCNTs, the rule is broken and, e.g., the $(5,0)$ SWCNT is considered metallic according to theoretical predictions. ${ }^{34}$ Thus, the relationship between the diameter, chirality and $E_{\mathrm{g}}$ is of great interest, especially in terms of borderlines between metallic and semiconducting nanotubes. Nevertheless, dividing $(n, m)$ SWCNTs into families according to their $\lambda=\bmod (n-m, 3)$ value is still generally valid and will also be used in this work.

Our earlier theoretical modeling studies on linear acenes, cyclacenes and finite SWCNTs showed a sensitivity of $E_{\mathrm{g}}$ to the size (length or diameter) of the studied system. ${ }^{35,36}$ Furthermore, $E_{\mathrm{g}}$ converged in a regular and smooth (exponential-like) way toward values close to zero upon extending the length of polyacenes (linear polyaromatic hydrocarbons ${ }^{35,36}$ ), which are considered to be fragments of infinitely wide nanotubes. 
The convergence was less regular and more scattered in the case of growing cyclacenes (in terms of their diameter). ${ }^{34,36}$ It is generally accepted that the chemical reactivity of such molecular systems decreases with the increase of their $E_{\mathrm{g}}$ value. $^{37,38}$ For example, a very small $E_{\mathrm{g}}$ value of longer polyacenes is related to their high reactivity reflected by difficulties in experimental synthesis. $^{39}$ It is known that benzene and the first homolog members of linear acenes (naphthalene, anthracene, tetracene and pentacene) are stable, planar molecules well characterized experimentally, and the next longer homologues are getting more and more reactive. ${ }^{31,40-45}$ Their electronic structure and reactivity are related to open-shell ground states. ${ }^{45}$ Nanocarbon compounds are very important in electronics as "versatile organic semiconductors" and their practical use is possible due to various substituents stabilizing the "core" of the molecule. ${ }^{42}$

In contrast to linear acenes, sometimes called oligoacenes, ${ }^{40,41}$ no zigzag type cyclacenes have been known experimentally. ${ }^{5,31,46,47}$ Interestingly, the concept of belts formed by $[n]$-cyclacenes was proposed by Heilbronner in the middle of the last century. ${ }^{48}$ As in the case of longer acenes, the cyclacenes are characterized by open-shell singlet ground states. ${ }^{5}$

The energy gap of SWCNTs is inversely proportional to their diameter. ${ }^{49} E_{\mathrm{g}}$ values of about $3.17,1.27$ and $1.14 \mathrm{eV}$, respectively, were recently modeled for three $(n, 0)$ zigzag cyclacenes ( $n=4,6$ and 8). ${ }^{36}$ Obviously, upon enlarging the tube diameter these structures converge toward nearly non-curvy systems with a flat surface, typical for graphene with the limiting value of $E_{\mathrm{g}}=0$. At the same time, we observed a smaller $E_{\mathrm{g}}$ value of $1.08 \mathrm{eV}$ for a $(4,0)$ zigzag nanotube consisting of 5 bamboounits, which was substantially smaller than the $E_{\mathrm{g}}$ obtained for the corresponding $(4,0)$ cyclacene (i.e. the shortest tube with an analogous diameter).

Unlike typical chemical synthesis, which is prone to produce a desired product (preferably a single chemical compound with only a small amount of side-products), ordered carbon systems are obtained as a highly non-uniform mixture of slightly different products accompanied by amorphous carbon and often also metallic impurities from the catalyst. ${ }^{4}$ Thus, it is difficult to separate individual products, for example carbon nanotubes or fullerenes, of desired characteristics. Besides, any kind of characterization of various nano-products is very challenging and relies mostly on microscopic examination $\left(\mathrm{AFM}^{50}\right)$, often supported by X-ray diffraction or UV-VIS or NIRF spectroscopy. ${ }^{4,8}$ Their purity is typically determined using thermogravimetric analysis. Another method used in examining the CNT and graphene products is Raman spectroscopy that often supports X-ray and microscopic determination of SWCNTs' structural parameters. ${ }^{4,10,51-57}$

In general, there are two main features in the Raman spectra of carbon nanotubes: the radial breathing mode (RBM) and tangential mode vibrations that form the so-called G-band. It has been observed that the RBM ( $A_{1 \mathrm{~g}}$ symmetry) can serve as a convenient parameter for the determination of the tube diameter as the frequency is inversely proportional to the tube diameter. ${ }^{4,10,51-54,58}$ A general relationship between the $\mathrm{RBM}$ frequency $\left(\omega_{\mathrm{RBM}}\right.$ in $\left.\mathrm{cm}^{-1}\right)$ and the nanotube diameter $d$ (in $\mathrm{nm}$ ) can be defined for a common SWCNT of selected chirality as: ${ }^{57,59-61}$

$$
\omega_{\mathrm{RBM}}=\frac{\pi c_{1}}{a_{\mathrm{C}-\mathrm{C}} \sqrt{3\left(n^{2}+n m+m^{2}\right)}}+c_{2}=\frac{c_{1}}{d}+c_{2}
$$

where the carbon-carbon distance $a_{\mathrm{C}-\mathrm{C}}=0.144 \mathrm{~nm}, c_{1}$ and $c_{2}$ are empirically derived parameters $\left(223.5\right.$ and $12.5 \mathrm{~cm}^{-1}$, respectively) and $n$ and $m$ are integers that define the diameter of zigzag $(n, 0)$ or armchair $(n, m)$ carbon nanotubes. Several other empirical formulas can also be found: ${ }^{62}$

$$
\omega_{\mathrm{RBM}}=\frac{248}{d}
$$

or

$$
\omega_{\mathrm{RBM}}=\frac{219}{d}+15
$$

Since the RBM decreases with increasing tube diameter and the RBM in the limit of infinite diameter yields unrealistic frequencies, more sophisticated formulas based e.g. on a cubic expansion have been reported. ${ }^{63}$ Note that in the low frequency region there are two other bands ( $\mathrm{E}_{1 \mathrm{~g}}$ and $\mathrm{E}_{2 \mathrm{~g}}$ symmetry) structurally related to the diameter, e.g. the elliptical deformation mode (EDM), ${ }^{63}$ and similar formulas to eqn (1) can be defined for those modes. ${ }^{64}$

The second most important Raman feature of SWCNTs, the $\mathrm{G}$-band, is related to the graphite $\mathrm{E}_{2 \mathrm{~g}}$ mode. This vibration splits in SWCNTs theoretically into six modes, corresponding to pairs of the $A_{1 g}, E_{1 g}$ and $E_{2 g}$ symmetries. The folding of the Brillouin graphite zone into a 1D SWCNT zone causes the splitting of the $\mathrm{E}_{2 \mathrm{~g}}$ mode. The symmetry of the system thus lowers and two new directions (axial and circumferential) can be distinguished. ${ }^{58,65}$ The shape of the G-band between 1500 and $1600 \mathrm{~cm}^{-1}$ allows distinguishing between semiconducting and metallic nanotubes. Two differently intense peaks are usually observed within the G-band region of semiconducting SWCNTs. The lower-frequency Lorentzian-shape band $\omega_{\mathrm{G}}^{-}\left(\sim 1550 \mathrm{~cm}^{-1}\right)$ corresponds to vibrations along the circumferential direction, while the higher band $\omega_{\mathrm{G}}^{+}$ ( $\sim 1590 \mathrm{~cm}^{-1}$ ) belongs to vibrations occurring along the tube axis. The metallic tubes exhibit the $\omega_{\mathrm{G}}{ }^{-}$band fitted with a Breit-Wigner-Fano line shape ${ }^{66,67}$ and with comparable intensity as the usually dominant $\omega_{\mathrm{G}}^{+}$band. Regarding the type of vibration involved, it is obvious that $\omega_{\mathrm{G}}^{+}$is not much dependent on the tube diameter, while $\omega_{\mathrm{G}}^{-}$exhibits the strong dependence on the curvature, and hence on the diameter. There are also other bands in the higher frequency region corresponding to combination modes of the G-band and RBM or 2xRBM, respectively, which are weak though.

Technical demands in materials science also stimulated theoretical studies on carbon nanomaterials. In particular, many DFT based studies on structural parameters, energetics or spectral properties (mainly NMR) of SWCNTs have been reported. ${ }^{36,68-74}$ Despite the fact that the Raman scattering is one of the most common methods investigating SWCNTs experimentally, theoretical studies on Raman characteristics of nanotubes 
using the first-principles methods are still rather rare. Popov et al. using the tight binding approach studied Raman features of pristine nanotubes. ${ }^{75,76}$ Aydin using the plane-wave based density functional theory modeled Raman spectra of single- or double-walled carbon and boron-nitride nanotubes, as well as their derivatives. ${ }^{18,63,64}$ Recently Saidi focused on the simulation of Raman characteristics of defected carbon nanotubes using the first-principles methods. ${ }^{77-79}$ Recently, we reported on the impact of $-\mathrm{OH}$ and $-\mathrm{COOH}$ carbon nanotube endsubstituents on structural changes, RBM, ${ }^{13} \mathrm{C}$ chemical shifts and HOMO-LUMO gaps of ultra-thin $(4,0)$ zigzag SWCNTs. ${ }^{34,80-82}$ No detailed studies on the prediction of RBM and G-band frequencies of large $(n, 0)$ zigzag cyclacenes as the shortest models of SWCNTs have been published yet. There is an open question if the theoretical RBM and G-band frequencies of cyclacenes could accurately substitute these spectral features in SWCNTs with diameters larger than $0.5 \mathrm{~nm}$. Besides, what is the nanotube length, i.e. the minimal number of bamboo-units, enabling reliable reproduction of experimental RBM or G-band parameters?

The aim of the current study is to answer the above stated questions. Thus, we will verify the possibility of reliable theoretical prediction of structures, energetics and Raman vibrational frequencies of real-size $(n, 0)$ zigzag SWCNTs using models of cyclacenes and nanotubes of different diameters and lengths. DFT characterization of finite-size fragments of selected carbon nanotubes with lengths up to $2.14 \mathrm{~nm}$ and diameters up to $1.2 \mathrm{~nm}$ will be performed. We estimate the rim effect of hydrogens in our pristine models and show the dependence of the studied parameters on the model length. In particular, the potential use of cyclacenes, ${ }^{35,39,83,84}$ as the shortest and simplest models of SWCNTs, will be discussed.

The DFT is considered as a fairly good method for predicting vibrational wavenumbers. It overestimates experimental values significantly less than the Hartree-Fock method, especially for the $\mathrm{C}-\mathrm{H}, \mathrm{N}-\mathrm{H}$ and $\mathrm{O}-\mathrm{H}$ stretching modes ${ }^{85-88}$ The latter method could produce $5-10 \%$ errors. It is significantly more difficult to calculate accurate vibrational intensities. Therefore, in the current study we will limit our predictions to the RBM and G-band frequencies.

The obtained results should provide a reasonably accurate and time-effective way for predicting spectral features of endfunctionalized SWCNTs, ${ }^{3,33,89,90}$ and chiral nanotubes or conjugates of nanotubes with biomolecules (e.g. hyaluronic acid-nanoparticles for medical applications) where the standard periodic calculations are not feasible due to the large system size (large unit-cells necessary for the periodic-boundary calculations).

\section{Computational details}

Two distinct model systems were chosen: $(n, 0)$ zigzag type cyclacenes and finite length $(n, 0)$ zigzag SWCNTs (Fig. 1). These models were constructed from a single benzene ring joined with next ones to form closed molecular loops (belts, bamboo-units) and by systematically increasing their diameter from 0.4 to $1.2 \mathrm{~nm}$ (see also ref. 35, 39, 83, 84). SWCNTs of three

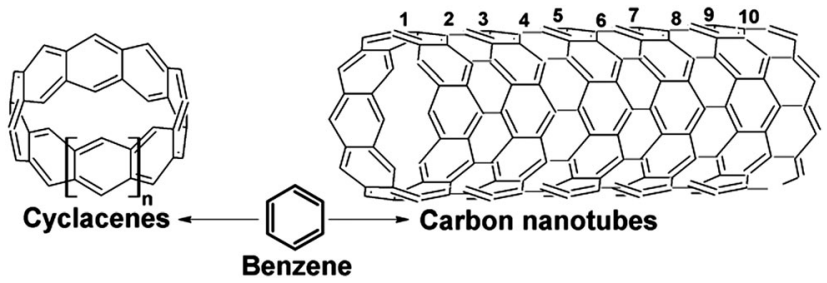

Fig. 1 Benzene as a basic building block of $(n, 0)$ zigzag cyclacene belts $(n=5-16)$ and $(n, 0)$ zigzag SWCNTs formed by 10 cyclacene belts $(n=5-9)$.

different lengths were constructed consisting of 4,6 and 10 bamboo-units with the longest size of $2.14 \mathrm{~nm}$. Obviously, one should be aware that typical real-size SWCNTs are still significantly longer. Nevertheless, the diameter of our models is of comparable size to experimentally observed narrow carbon nanotubes.

All DFT calculations for finite size models were performed using the Gaussian 09 program. ${ }^{91}$ A hybrid B3LYP density functional ${ }^{92,93}$ combined with the $6-31 \mathrm{G}^{*}$ basis set was used. The unrestricted approach (UB3LYP ${ }^{94}$ ) was used for the better description of open-shell singlet states in polyaromatic systems (see also our earlier study ${ }^{36}$ ). Optimizations were carried out using the loose symmetry, tight SCF and optimization thresholds, and the grid-size of 150590 . The calculations of vibrational frequencies, including harmonic and Raman active frequencies, for all optimized geometries (confirming also the minimum on the potential energy surface), were performed at the same level of theory.

Alternatively, for 10-unit $(n, 0)$ SWCNTs with $n>9$, where the fully DFT approach appeared to be computationally too demanding, the Raman frequencies were obtained by the Cartesian coordinate tensor (CCT) transfer $^{95}$ using the library comprising seven shorter pristine nanotubes (Fig. 2). From the target 10-unit SWCNT structure, shorter fragments containing 4 bamboo-units were generated along the entire tube by its fragmentation. The Cartesian Hessian (second energy derivatives) and polarizability tensors were transferred atom-by-atom, according to the local best overlap of the target 10-unit SWCNT with the library geometries. Then the Hessian was diagonalized and vibrational normal modes thus obtained were combined with the polarization tensors to provide the backscattered Raman intensities. ${ }^{96}$ Parameters for shorter library tubes were obtained at the B3LYP/6-31G* level of theory. Note that although the polarization tensors and the Hessian were calculated using the Gaussian program, any other available program providing these characteristics (e.g. Dalton, Orca, Turbomole, etc.) could be basically exploited if it provides explicitly the Hessian matrix $F_{\mathrm{i} \alpha \mathrm{j} \beta}$ and the polarizability tensors $\alpha_{\alpha \beta}$.

The CCT approach has been shown as an efficient way for simulating the vibrational spectra of large molecules ${ }^{97}$ or very flexible systems. ${ }^{98,99}$ This method is based on an idea of a molecule being a system of individual groups each having a dipole moment, electric dipole-electric dipole polarizability, magnetic dipole-electric dipole polarizability, etc. ${ }^{100}$ For the Raman tensors (polarizability derivatives) mutual interactions 


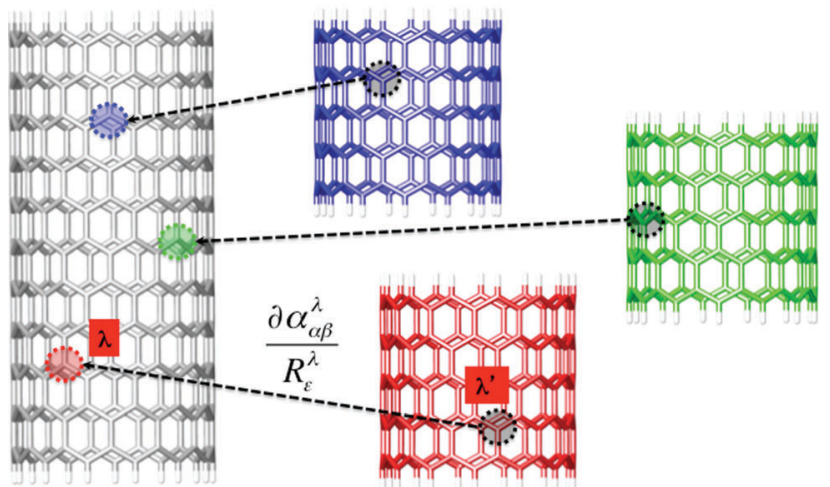

Fig. 2 Schematic description of the tensor transfer CCT approach: for each atom $\lambda$ of a real-size nanotube (left, grey), the tensor derivatives (e.g., of polarizability $\alpha$ ) were transferred from shorter tubes (right) providing the best local overlap. The force field (second energy derivatives) comprising two atoms was transferred similarly.

between groups need to be considered even in the independent group model. Then, molecular properties are written using a common origin, while the group properties are considered in terms of local origins, in order to derive the dependence between groups. The total tensors are then expressed as sums of individual group contributions accounting for both origin-dependent terms and mutual polarization terms. Only the electric dipolar interaction is taking into account the mutual polarization terms. Thus, the polarizability tensor can be expressed as: ${ }^{101} \alpha_{\alpha \beta}=\sum_{i} \alpha_{i, \alpha \beta}+\sum_{j \neq i} \alpha_{i, \alpha \chi} T_{i, j, \chi \varepsilon} \alpha_{j, \in \beta}$, where the tensor $T_{i, j, \alpha \beta}$ is the distance tensor defining the mutual positions of interacting groups.

The energy gaps $\left(E_{\mathrm{g}}\right)$ for optimized structures were derived from energies of the HOMO and the LUMO. Estimations of selected parameters of finite-size models of infinitely long tubes (or very large diameters) were performed using a typical two-parameter formula, ${ }^{102}$ which is efficient in estimating electronic energies and energy related parameters in the complete basis set (CBS) limit. ${ }^{102,103}$

Additionally, calculations on infinitely long $(n, 0)$ SWCNTs, with $n=6-15$, were performed using the plane-wave based density functional theory first-principles method as implemented in the CASTEP code. ${ }^{104}$ Using the code, the initial structures of pristine SWCNTs within the hexagonal unit-cell of appropriate size in $a$ and $b$ directions ensuring an inter-tube separation of $\sim 0.8 \mathrm{~nm}$ were optimized (the cell parameters were not optimized) and then Raman transitions were calculated. A Monkhorst-Pack $k$-point grid of dimensions $(1,1,50)$ has been used for all isolated SWNTs where $m$ was determined to ensure the convergence of the total energy, force constants, and Raman intensities with acceptable numerical precision. The $\mathrm{PBE}^{105}$ functional along with the norm-conserving pseudopotential (OP_00PBE) was used in all periodic calculations. Besides, the "ultra-fine" $680 \mathrm{eV}$ plane wave basis set cut-off, BFGS optimization method, "precise settings" of convergence criteria $\left(1 \times 10^{-6} \mathrm{eV}\right.$ for the energy convergence and $1 \times 10^{-5} \mathrm{eV}$ for the Efield energy tolerance) were set up. Raman intensities defined as changes in polarizability of the compounds under excitation of a phonon mode $(\partial \alpha / \partial R)$ were calculated using the hybrid Gonze's variational DFPT ${ }^{106} /$ finite-displacement method. No additional scaling was used for the Raman features.

\section{Results and discussion}

\section{Convergence of the structural parameters of SWCNTs}

Obviously, the characteristic structural parameters of benzene rings (the aromatic CC bond length is $\sim 1.40 \AA$ and the CCC bond angle is $\sim 120.0$ degrees), considered as the main building blocks of finite carbon nanotubes ${ }^{35}$ in the current study, will change in a regular way upon gradually extending the system in all three dimensions. In the limiting case for a very large tube diameter, we could assume a typical $\mathrm{sp}^{2}$ carbon character (CCC angle of $\sim 120$ degrees), like in planar benzene molecules. In the case of smaller tube diameters, the CCC angles will decrease due to a partial $\mathrm{sp}^{2}$ carbon atom re-hybridization toward $\mathrm{sp}^{3}$ (in the limit it will reach 109.7 degrees, and $1.54 \AA$ for a single CC bond). As a result of increasing nanotube length it is reasonable to expect some convergence of geometrical parameters to a certain value for relatively long nanotubes far from values at nanotube rims. Thus, in real-size systems the inner part of the tube should be practically unaffected by the edges. Indeed, by selecting two kinds of CC bonds, parallel to the tube axis (f-type) and at the $\sim 60$ degree angle to the axis (c-type) it is possible to demonstrate the above mentioned statements in our models of $(n, 0)$ zigzag CNTs formed by 10 bamboo-units (Fig. 3). For brevity, the calculated CC bond lengths and CCC angles, with bond and angle numbering shown, are gathered in Tables S1 and S2 in the ESI. $\dagger$ The CC bonds at the rim differ significantly from corresponding internal CC bonds due to the rim effects, caused by carbon atoms capped with hydrogens (for pristine SWCNT). In principle, characteristic elongation (c-type) or shrinking (f-type) patterns of CC bond lengths could be observed for tubes of different curvatures (diameter) as a function of the distance from the rim. Such patterns for different kinds of bond lengths shown in Fig. 3 follow symmetric "U-letter" or upside-down "U-letter" shapes, respectively. The biggest difference between the c-type CC lengths (Fig. 3, right panel) at the rim and in the middle of the tube can be found for tubes of the smallest diameters $(n=5)$ and can reach up to $0.030 \AA$, while for wider SWCNTs the difference decreases to $0.015 \AA$. Similar effects with different amplitudes are observed for the f-type bonds. Note that while the f-type bonds decrease their length from the rim to the middle, an opposite trend is found for the c-type bonds. In contrast, the f-type bonds are getting longer with increasing diameter, while the c-type bonds are getting shorter. The difference in bond lengths among nanotubes of different diameters in the middle of the tube (bond No. 5-6) shows a span of about $\sim 0.035 \AA$.

Variations of CCC bond angles in the model pristine $(n, 0)$ zigzag SWCNTs with regularly growing diameter from 0.4 to $0.7 \mathrm{~nm}$ (i.e. $n=5,6,7,8$ and 9) are shown in Fig. S1 (ESI $\dagger$ ). 

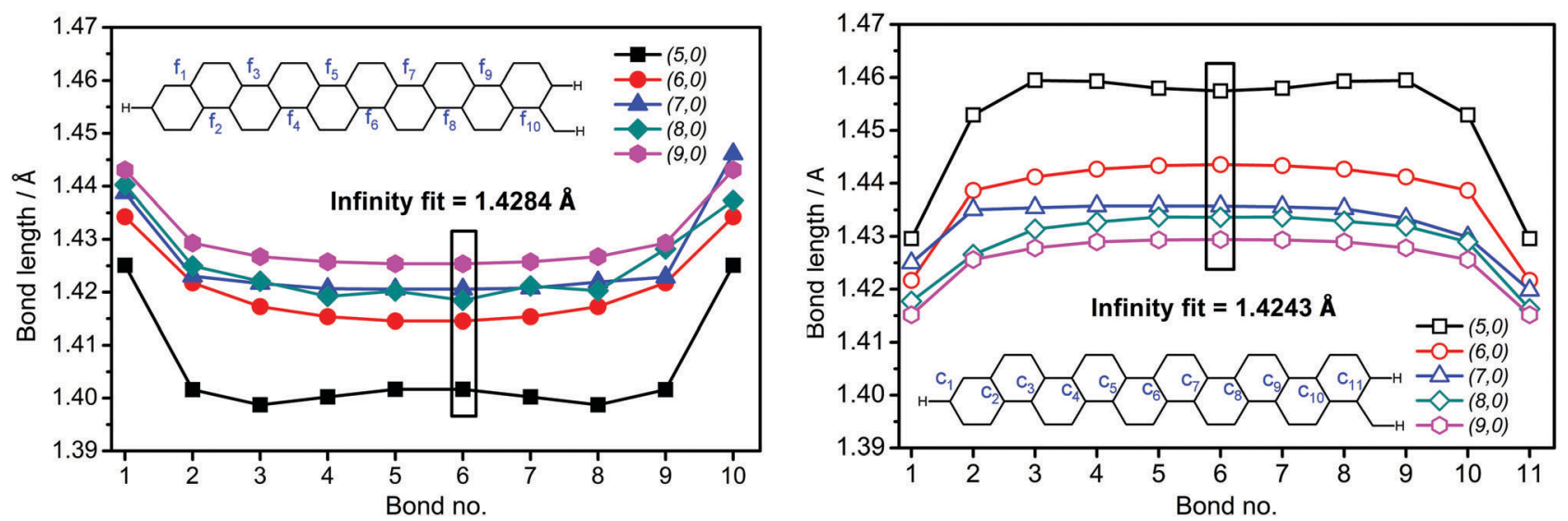

Fig. 3 CC bond length patterns of two types of bonds along the SWCNT tube axis: (left) f-type and (right) c-type. Pristine 10-unit long zigzag ( $n$, 0) SWCNTs with increasing diameter $(n=5-9)$ were inspected. Lines connecting the points are provided to show trends. Extrapolation of the distances to an infinitely wide SWCNT is indicated by the "Infinity fit" value.

Two angles $\alpha$ and $\beta$ were selected and their meaning is also depicted in Fig. S1 (ESI $\dagger$ ). Notice a scattering of angle values when going from one rim toward the other one (for example, the $\alpha$ angle starts from the left end as $\mathrm{C}(\mathrm{CH}) \mathrm{C}$, and on the right end is formed by the $(\mathrm{CH}) \mathrm{C}(\mathrm{CH})$ angle). The $\mathrm{CCC}$ value scattering close to the rim is less pronounced for larger diameter tubes. A larger dependence of the $\alpha$ angle than the $\beta$ type on the diameter, as well as on the distance from the rim is apparent from Fig. S1 (ESI $\dagger$ ). The $\alpha$ bond angle changes from $\sim 112$ degrees $(n=5)$ to an average value of $\sim 118$ degrees $(n=9)$. In contrast, the $\beta$ angle is nearly constant ( $\sim 120$ degrees). Another conclusion made in Fig. S1 $(\mathrm{ESI} \dagger)$ is that the rim effect on CCC angles practically vanishes after more than three benzene layers from the rim.

\section{HOMO-LUMO gap}

Changes in the HOMO-LUMO energy gaps (in eV) upon increasing the diameter of $(n, 0)$ cyclacenes $(n=4$ to 16$)$ and 4-, 6- and 10-unit long $(n, 0$; where $n=4-12)$ SWCNTs are presented in Fig. 4. It is apparent from the figure that upon increasing the tube diameter from $0.4 \mathrm{~nm}$ to $0.70 \mathrm{~nm}$ a significant change in the HOMO-LUMO energy gap occurs (from -1.2 to $-0.1 \mathrm{eV}$ ). The general pattern of changes in $E_{\mathrm{g}}$ according to increasing diameter is the same for both cyclacene models and SWCNTs. Only the values for cyclacenes are shifted toward larger $E_{\mathrm{g}}$. We see the $E_{\mathrm{g}}$ value approaching a limiting value of $\sim-1.1 \mathrm{eV}$ for cyclacenes, while for SWCNTs it is getting closer to $0 \mathrm{eV}(\sim-0.2 \mathrm{eV})$ as is the value for graphene. In addition, the changes in $E_{\mathrm{g}}$ resulting from the model increase (both in its diameter and lengths) are shown in Fig. S2 (ESI $\dagger$ ). The energy gap after the initial big decrease (absolute value) stabilizes at a certain value for longer tubes (more than 3 bamboo-units) and $n>8$.

HOMO, and LUMO values and the corresponding energy gaps calculated at the B3LYP/6-31G* level are gathered in Table S3 (ESI $\dagger)$. The $E_{\mathrm{g}}$ values reproduce accurately the earlier calculated values ${ }^{5}$ (only in the case of the $(11,0)$ system a difference of about $0.4 \mathrm{eV}$ is observed). Similar data for selected finite models of $(n, 0)$ SWCNTs, where $n$ is $1-10$ and the longest model contains 10 bamboo-units, are shown in Table S4 (ESI $\dagger$ ).

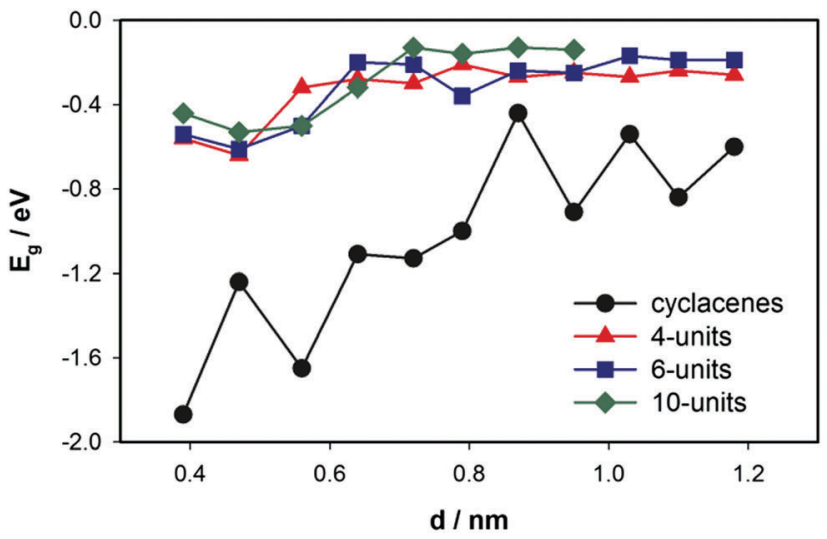

Fig. 4 The B3LYP/6-31G* calculated HOMO-LUMO gap ( $E_{\mathrm{g}}$ in eV) vs. diameter $d$ (in $\mathrm{nm}$ ) for selected pristine 4-unit, 6-unit and 10-unit long zigzag $(n, 0)$ SWCNTs, respectively, and the corresponding cyclacenes. Lines connecting the points are provided to show trends.

Unfortunately, due to computational burden, the calculations for larger diameter SWCNTs $(n>12)$ could not be performed. Nevertheless, calculated data for very large ordered carbon systems are available in the literature. ${ }^{3,33,89,90}$ A number of authors employed periodic boundary calculations on a crystal cell and thus obtained data for theoretical infinite tubes. For example, Zhou et al. ${ }^{107}$ observed, using the B3LYP/6-31G* calculations, a decrease of absolute value of $E_{\mathrm{g}}$ with the elongation of the $\mathrm{C}_{20} \mathrm{H}_{20}$ fragment of finite-size metallic $(5,5)$ armchair SWCNTs. The $E_{\mathrm{g}}$ decreased systematically until it reached a converged value of $\sim 1.0 \mathrm{eV}$ for $\mathrm{C}_{200} \mathrm{H}_{20}$.

\section{Raman radial breathing mode (RBM)}

Although $(n, 0)$ cyclacenes represent the simplest, and often an imperfect model of SWCNTs, we have observed ${ }^{35,36}$ on a set of small selected cyclacenes a direct correlation between their diameter and the RBM frequency, similar to the relationship found for SWCNTs. ${ }^{55,59,60,61}$ Molecular vibrations characterizing the RBM are depicted in Fig. 5. Note that G-band characteristics can be simulated using the cyclacene models only 


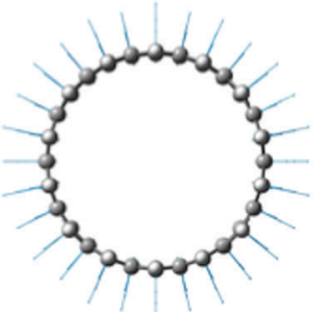

RBM

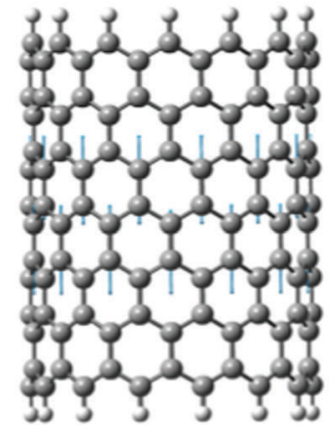

$\omega^{+}$G-band

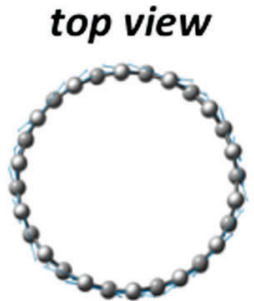

side view

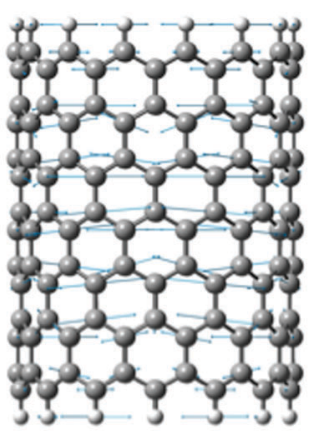

$\omega^{-}$G-band
Fig. 5 Molecular motions for selected vibrational bands (RBM, $\omega^{+}$and $\omega^{-}$ G-bands) as calculated for the $(14,0) 6$-unit long SWCNT.

approximately and will be discussed briefly in the next chapter. In this study, the rim effects were minimized using significantly longer finite tube models comprising 10 bamboounits. Calculated RBM frequencies upon increasing the diameter of isolated infinite SWCNTs (CASTEP calculations) or as isolated finite-length tubes are presented in Fig. 6. Data obtained with the empirical relation from eqn (1) are shown for comparison. Detailed comparison of individual theoretical approaches is summarized in Table S5 (ESI†), which comprises also results obtained for shorter SWCNTs (4 and 6 bamboo-units; optimized at the B3LYP/6-31G* level, Raman frequencies were acquired at the same level). Our DFT calculations reproduce a fairly well reported dependence of SWCNTs' RBM frequencies on the diameter. ${ }^{12,14,16,18,22,108}$

The CASTEP data for infinite tubes were taken as reasonable references, because they represent a model closest to real SWCNT samples. A closer look at the left panel of Fig. 6 (or Table S5, ESI $\dagger$ ) reveals that significantly poorer description of RBM is obtained for very narrow $(6,0)$ metallic tubes, where the surface of the tube is very distorted. Note that RBM of another metallic tube $(9,0)$ SWCNT calculated using the 4-unit model also shows a significantly large deviation $\left(33 \mathrm{~cm}^{-1}\right)$ from the CASTEP value. Nevertheless, RBM converges with the increase of the model length to $329 \mathrm{~cm}^{-1}$ obtained with the 10-unit model that is close to the CASTEP value $\left(324 \mathrm{~cm}^{-1}\right)$. Fortunately, this problematic convergence of RBM with respect to the system size in metallic tubes slowly disappears for wider tubes. This significantly slower convergence of calculated Raman frequencies in the case of metallic tubes with respect to the model size was also observed by Saidi. ${ }^{78}$ The author obtained a blue shift upon increasing his model, while we observed a red shift. Note that Saidi used plane wave based DFT calculations with a unit cell containing three or four bamboo-units. It is also noteworthy that his RBM value for the $(9,0)$ SWCNT is significantly lower (239 or $275 \mathrm{~cm}^{-1}$; according to the model length) than our values or any published RBM summarized in Table S5 (ESI $\dagger$ ). Thus, it is apparent that slightly longer models (6-units) are necessary for correct predictions of RBM frequencies for metallic SWCNTs compared to semiconducting ones.

Data for the $(5,0)$ SWCNT were not obtained due to convergence problems. Thus, these tubes were excluded from the analysis of RMSD (see Table S5, ESI $\dagger$ ) of calculated RBM obtained using finite-size models from infinite CASTEP calculations. It can be summarized that all DFT models of finite-length tubes or cyclacenes reproduce the CASTEP RBM with a relatively high precision (RMSD smaller than $20 \mathrm{~cm}^{-1}$ ). Raman characteristics for long SWCNTs (10-units) with bigger diameters $(n>9)$ were obtained using the CCT transfer approach. Interestingly, the average error of RBM for cyclacenes is smaller than or comparable (RMSD $\pm 8 \mathrm{~cm}^{-1}$ ) with longer models (4- and 6-units) of SWCNTs. This is also apparent from Fig. 6 (right panel), where the correlation of cyclacenes' results with the CASTEP data on infinite tubes was slightly better than for finite-length SWCNTs. The RBM frequencies obtained with eqn (1) are even closer to the CASTEP results (RMSD of about $4 \mathrm{~cm}^{-1}$ ). Note that the error for 10-unit long SWCNTs is the smallest among all finite-length models $\left(\sim 5 \mathrm{~cm}^{-1}\right)$. Nevertheless, it can be concluded that a significantly less computationally demanding model of zigzag $(n, 0)$ cyclacene is sufficiently accurate to predict the RBM frequencies of zigzag $(n, 0)$ SWCNTs of the same radius.

There is a similar vibration to RBM in our finite-length models of pristine cyclacenes or nanotubes that is coupled with RBM. It is the symmetric wagging of hydrogen atoms at rims of tubes, which contaminates the spectrum at lower frequencies. A dependence of this vibrational mode upon increasing of the model diameter is depicted in Fig. S3 (ESI $\dagger$ ) for $(n, 0)$ cyclacene and SWCNTs consisting of 4 bamboo-units. It is obvious that for the SWCNT model the wagging mode frequency decreases with increasing diameter until it reaches approximately the same value as RBM for SWCNTs with $n>11$. The wagging mode behaves differently in cyclacenes though. It started as a lower-frequency mode (compared to RBM) for small diameter cyclacenes. Then, while the RBM frequency decreases with the system diameter, the wagging mode remains approximately the same (max. deviation from an average value is $24 \mathrm{~cm}^{-1}$ ). Such behavior can be to some extent explained by exploring the potential energy distribution (PED) of internal coordinates for selected stretching $(\nu)$, bending $(\delta)$, and torsion $(\tau)$ vibrations displayed in Fig. S4 and S5 (ESI $\dagger$ ) showing only subtle differences in $\delta(\mathrm{CCH})$ and $\tau(\mathrm{CCCH})$ patterns of cyclacenes and SWCNTs.

\section{Tangential G-band}

Tangential modes refer to all phonon bands of a SWCNT originating from the optical phonons of graphite. The tangential 

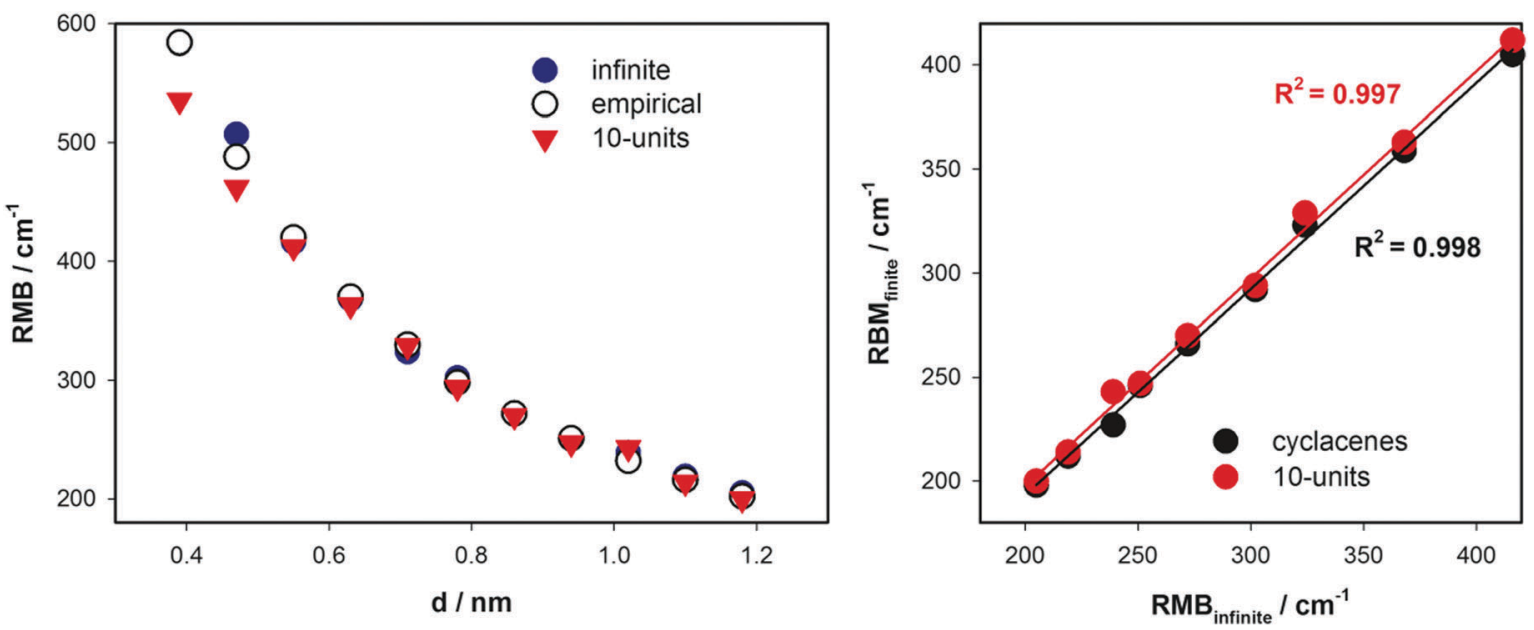

Fig. 6 Convergence patterns of Raman RBM wavenumbers $\left(\mathrm{cm}^{-1}\right)$ vs. diameter $d(\mathrm{~nm})$ of SWCNTs (left). The results obtained by three different approaches are displayed: CASTEP calculations of isolated infinite SWCNTs (blue full circles), the B3LYP/6-31G(d) DFT calculation of isolated 10-unit long SWCNTs (red triangles) and estimation of vibrational frequencies using empirical eqn (1) (empty circles). Calculated RBM on finite models (cyclacenes or 10 -unit long SWCNTs) are related to calculations on infinite tubes performed in CASTEP on right. Two narrowest SWCNTs $(5,0)$ and $(6,0)$ were excluded from the correlation.

modes involve predominantly the $\mathrm{sp}^{2}$ in-plane carbon-carbon bonds that are extremely strong. The most intense Ramanactive vibrations of the tangential modes manifest in the Raman spectrum as the G-band. It was experimentally observed on sets of SWCNTs with the diameter from $\sim 1 \mathrm{~nm}$ to $\sim 3 \mathrm{~nm}$ that the position of the most intense G-band feature, $\omega_{\mathrm{G}}^{+}$ $\left(\sim 1590 \mathrm{~cm}^{-1}\right)$, corresponding to vibrations along the tube axis (Fig. 5), is only negligibly dependent on the tube diameter. ${ }^{65}$ In contrast, $\omega_{\mathrm{G}}^{-}\left(\sim 1550 \mathrm{~cm}^{-1}\right)$ corresponding to vibrations along the circumferential direction should depend on diameter $d$. The difference between SWCNT bundles and isolated nanotubes is small in this region $\left(\Delta \sim 2 \mathrm{~cm}^{-1}\right)$. The isolated SWCNTs provide bands with significantly smaller widths $\left(\sim 10 \mathrm{~cm}^{-1}\right.$ compared to $\sim 20 \mathrm{~cm}^{-1}$ in SWCNT bundles ${ }^{65,67,109}$ ). In this work we investigated the $\omega_{\mathrm{G}}^{+}\left(\mathrm{A}_{1 \mathrm{~g}}\right)$ and $\omega_{\mathrm{G}}^{-}\left(\mathrm{E}_{1 \mathrm{~g}}\right)$ frequencies for narrower SWCNTs of a diameter from 0.4 to $1.2 \mathrm{~nm}$. The efficiency of our finite-size models was estimated by a comparison with the CASTEP calculations on infinite isolated tubes and with reported experimental data. Calculated frequencies of the $\omega_{\mathrm{G}}^{+}$ are summarized in Fig. 7 according to the tube family. It can be seen that while for RBM the cyclacenes represented a reasonable model, for $\omega_{\mathrm{G}}^{+}$they provide too low frequencies no matter what $\lambda$-family is inspected. The 4 -unit models provide frequencies at an average of $\sim 1608 \mathrm{~cm}^{-1}$, which is slightly above experimental values $^{65}$ found for tubes with $d>1 \mathrm{~nm}$, nevertheless still closer to experiment than the cyclacenes' values with an average of $\sim 1530 \mathrm{~cm}^{-1}$. The 4-unit model provides already converged results with respect to the model length, because the $\omega_{\mathrm{G}}^{+}$ frequencies obtained using other two longer models are almost identical. Note that the frequencies for the 10-unit model were acquired by the CCT approach using the library of small 4-unit long fragments (see Computational details), and thus their similarity is obvious.

Calculated frequencies of $\omega_{\mathrm{G}}^{+}$for finite tubes well correspond to values for infinite-size tubes of $\lambda=1$ and $\lambda=2$ families. The average frequency for those two families is $1589 \mathrm{~cm}^{-1}$. Infinite SWCNTs of the $\lambda=0$ family exhibit an increase of $\omega_{\mathrm{G}}^{+}$frequencies with the increase of diameter converging to the value of $\sim 1580 \mathrm{~cm}^{-1}$ for SWCNTs of $d=1.2 \mathrm{~nm}$. Experimental data for isolated extremely narrow tubes $(d<0.5 \mathrm{~nm})$ are not available,
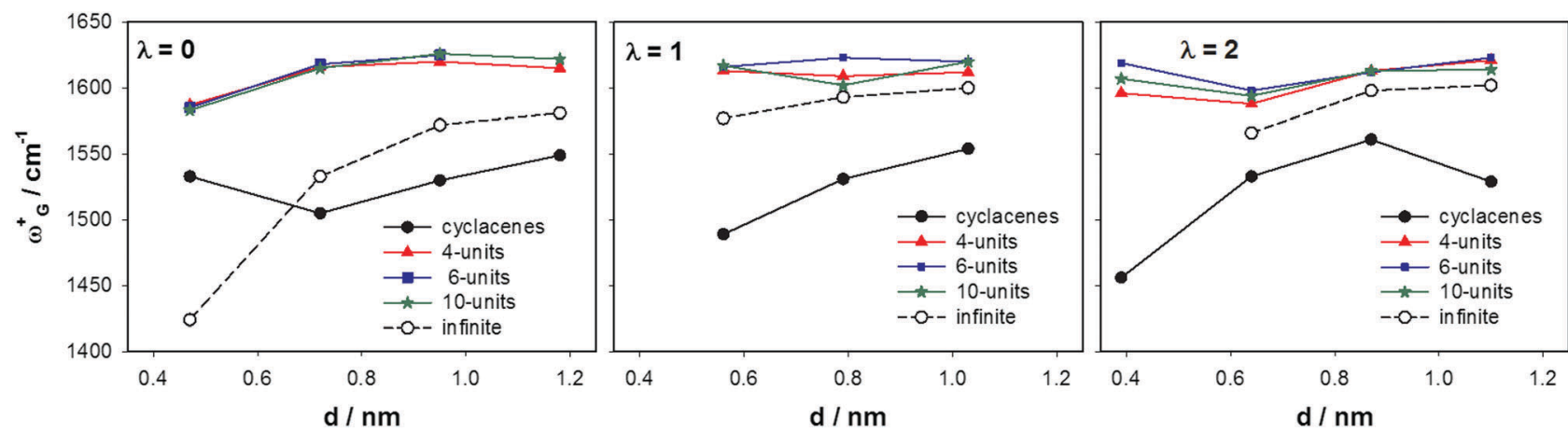

Fig. 7 Calculated frequency of $\omega_{\mathrm{G}}^{+}$for various SWCNT models as a function of their diameter $d(\mathrm{~nm})$. Wavenumbers of isolated infinite tubes calculated in CASTEP are shown for comparison. Plots show trends separately for $\lambda=0$ and $\lambda=1,2$ SWCNT families. 
nevertheless those few experimental frequencies for tubes with $d \sim 1 \mathrm{~nm}$ exhibit larger dispersion around the average value than e.g. tubes with $d \sim 1.5 \mathrm{~nm}$. ${ }^{65}$ It is also interesting that when the extreme case of the $(6,0)$ SWCNT is excluded, the cyclacene models of the $\lambda=0$ family provide the same trends of $\omega_{\mathrm{G}}^{+}$frequencies as the periodic CASTEP calculations even with close absolute values. Note that the data for the infinite $(5,0)$ SWCNT ( $\lambda=2$ family, $d=0.4 \mathrm{~nm}$ ) could not be obtained, because the calculations did not converge. Nevertheless, we could anticipate similar extreme behavior as the $(6,0)$ SWCNT $(\lambda=0$ family, $d=0.47 \mathrm{~nm})$. Since we saw the model-length dependence of $\omega_{\mathrm{G}}{ }^{+}$frequencies in our finite-size models, it is a question, whether something similar could not be seen (likely to a lesser extent) also for periodic calculations on infinite tubes. In this work, the unit cell consisting of only one ribbon of benzene rings was used. A larger unit cell consisting of more bamboo-units could lead to a shift of $\omega_{\mathrm{G}}^{+}$frequencies to slightly higher values. However, this was not part of this work and cannot be commented more.

Calculated frequencies of $\omega_{\mathrm{G}}^{-}$for infinite tubes, as well as for finite-length models, are presented in Fig. 8. In contrast to $\omega_{\mathrm{G}}^{+}$, there is a significant increase of frequency with the increase of diameter for all $\lambda$ families. In general, all finite-length models follow trends obtained for infinite tubes. Nevertheless, the cyclacene data are least regular. For the $\lambda=1$ family, the cyclacenes show too low frequencies, while for $\lambda=2$ they match the 4 -unit model. The data for the $\lambda=0$ family are more scattered but the trend is still obvious. The small-diameter tubes ( $n=5$ and 6$)$ again represent extreme cases for all models that do not fit to a linear trend line defining the $\omega_{\mathrm{G}}^{-}$increase with $d$. Nevertheless, it cannot be clearly said whether this is due to a computational error or due to the nature of the narrowtube surface, because experimental data for such narrow isolated nanotubes are not available. The 6-unit model frequencies practically match results for the 4-unit model, as well as results for 10-unit models and thus the 10-unit model data are not plotted in Fig. 8 for better transparency of the figure.

Reported experiments on isolated nanotubes also revealed the increase of $\omega_{\mathrm{G}}^{-}$frequency with the increase of diameter. ${ }^{65}$ However, the slope is less steep despite what was observed with our models. The authors showed a change of $\sim 30 \mathrm{~cm}^{-1} \mathrm{~nm}^{-1}$ for semiconducting and $\sim 50 \mathrm{~cm}^{-1} \mathrm{~nm}^{-1}$ for metallic nanotubes. All our models predicted 2-3 times faster increase than that shown experimentally. Thus, if experimental values for the tube of $d \sim 1 \mathrm{~nm}$ are $\sim 1540 \mathrm{~cm}^{-1}$ for semiconducting and $\sim 1520 \mathrm{~cm}^{-1}$ for metallic tubes, respectively, we can see that our CASTEP data well correspond to those values, while frequencies for finite-length models are overshot. In this context, frequencies for $\lambda=1$ cyclacenes seem to be in good agreement with experiment, but this is probably only due to a coincidental error cancelation. Nevertheless, again we would like to notify that experimental data reported in ref. 65 correspond to SWCNTs of $d$ usually larger than $1 \mathrm{~nm}$.

In the end, we would like to point out that to the best of our knowledge this is the first time the Cartesian Coordinate Tensor transfer technique was used to obtain the Raman frequencies of carbon nanostructures (here to obtain the frequencies for tubes of $n>9$ and length of 10 bamboo-units). This approach has been proven to provide Raman features of even whole proteins in reasonable quality, ${ }^{97}$ and thus its extension to nanomaterials was only a logical step. Note that even if the quality of the method can be for some (especially coupled or phonon) modes limited, it works perfectly for the RBM frequencies (an average error of $\pm 3 \mathrm{~cm}^{-1}$ between RBM obtained by the CCT and fully DFT; see Fig. S6, ESI $\dagger$ ). The agreement within the less local G-band modes is similar for RBM or lower but comparable with results for 4 or 6-unit models, because of the fact that only relatively short fragments (4-units) were used for the transfer.

Fig. S6 (ESI $\dagger$ ) showing the comparison of Raman active bands calculated for 10-unit long $(9,0)$ SWCNTs using the CCT approach and fully DFT also reveals some limitations of the transfer technique. Generally, for significantly delocalized phonon modes the quality of the transfer technique is supposed not to go much beyond the quality of transferring fragments that are used for building up the final spectrum of the targeted molecule (here 10-unit SWCNT). There is an artificial band splitting caused by rim effects in the $\omega_{\mathrm{G}}^{+}$region of small fragments. Carbons closer to the rim (consisting of hydrogen atoms in pristine tubes) in the 4-unit fragments vibrate with lower frequencies than the most inner carbons (not shown).
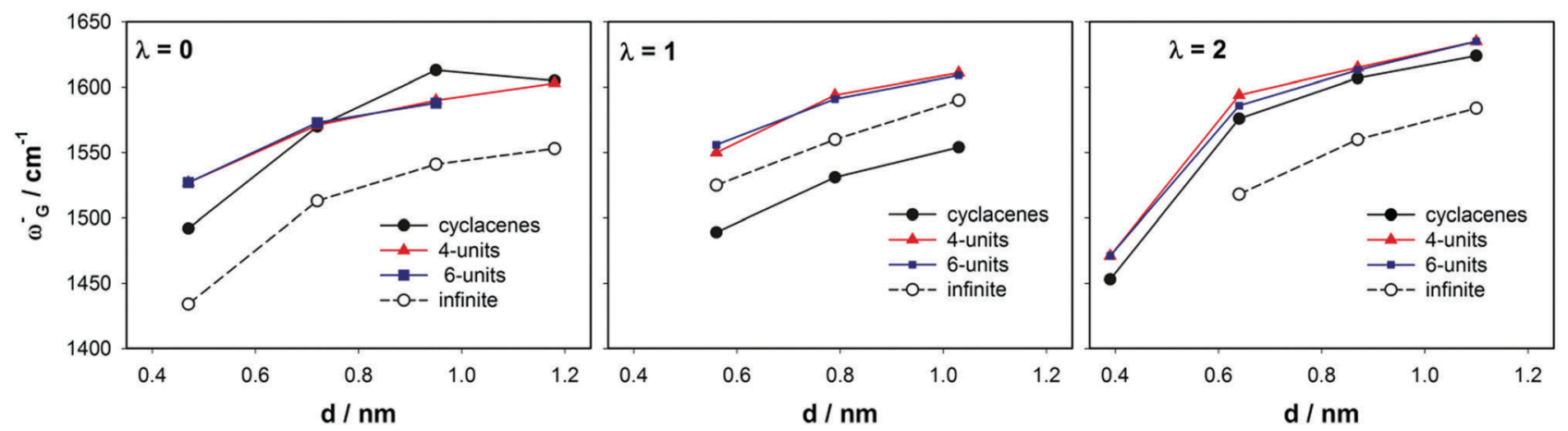

Fig. 8 Calculated frequency of $\omega_{\mathrm{G}}^{-}$for various SWCNT models as a function of their diameter $d(\mathrm{~nm})$. Wavenumbers on isolated infinite tubes calculated in CASTEP are shown for comparison. The results for 10-unit models practically copy data for 4-unit models and they are not shown for better transparency of the figure. Plots show trends separately for $\lambda=0$ and $\lambda=1,2$ SWCNT families. 
In such a model the inner carbons represent only small part of all carbon atoms and thus their vibrations manifest as a shoulder on the dominant $\omega_{\mathrm{G}}^{+}$band of carbons affected by the rim. With increasing size of the tube the effect of the rim diminishes, as seen for the fully DFT calculated tube in Fig. S6 (ESI $\dagger$ ), where the shoulder is almost undetectable. By transferring frequencies and intensities from the fragment to a large molecule, as done by the CCT technique, the splitting is also suppressed, but only to a certain extent (Fig. S6, ESI $\dagger$ ). It is mostly because the CCT transfers properties atom-by-atom, according to the local best geometry overlap between a carbon from the fragment and carbon in the target 10-unit SWCNT. We also tried to suppress the artifacts caused by light hydrogens in our pristine models by deleting the polarizability derivatives of hydrogen atoms before the final visualization of the spectra, but it works in the case of unlocalized modes only partly. Despite all aforementioned, it is clear that the transfer technique models the spectra of long nanotubes with accuracy comparable with fully DFT calculations. The accuracy of the CCT can be further increased if longer fragments are used for the transfer (6-units or beyond).

\section{Conclusions}

Cyclic acenes and H-capped finite-size zigzag ( $n, 0)$ SWCNTs were chosen to model structural and Raman parameters of realsize SWCNTs using the DFT methodology. The UB3LYP/6-31G* level of theory was used to fully optimize their structure and calculate the Raman active RBM and G-band vibrational frequencies. The size of studied carbon nanosystems varied from 5 to 15 conjugated benzene rings and the length of nanotubes was up to $2 \mathrm{~nm}$ (10 bamboo-units). Some regular changes (saturation of their values going from the rim to the middle of the tube) in the CC bonds and CCC angles upon increasing SWCNT diameter were observed. These parameters converged toward the limit values for diameters larger than $1 \mathrm{~nm}$. The RBM values calculated for cyclacenes and SWCNTs of the same diameter were very close to each other and in agreement with reported empirical formulas. A saturation of the RBM frequency upon enlarging the SWCNT diameter was observed. The Raman features for 10-unit long finite-size SWCNTs were also successfully modeled using the Cartesian Coordinate Tensor transfer technique.

This study demonstrates a possibility of using the DFT modeling on finite-length models instead of expensive calculations for periodic systems, to make realistic predictions of the Raman features for small diameter CNTs. We showed that $(n, 0)$ cyclacenes are often too crude models for reliable simulations of SWCNT properties. After all, calculations on $(n, 0)$ cyclacenes provided very accurate predictions of RBM values of $(n, 0)$ SWCNTs. Nevertheless, it might be only fortuitous accident. Starting from 4-unit long SWCNTs the quality of predicted properties, even positions of G-band features, becomes reasonable and obtained data well correspond to experiment or to theoretical data obtained for infinite tubes.
The 6-unit long models provide slightly better frequencies, especially for metallic tubes, but also reduce the rim effect of hydrogen atoms in pristine tubes. An increase of the model length (up to 10 bamboo-units model) usually does not bring any substantial improvement in achieved Raman frequencies. Thus, the 6-unit models seem to perform best in terms of an expense/accuracy ratio.

The results show a way, how to tackle the problem in modelling of Raman spectral features with reasonable accuracy and in an effective time-scale for nanotube systems, where the standard periodic calculations are not feasible (e.g. endfunctionalized SWCNTs, chiral nanotubes or conjugates of nanotubes with biomolecules like hyaluronic acid-nanoparticles for medical applications). Since typical studies on nanotubes deal with non-ideal structures having a certain amount of defects (dislocated or missing atoms etc.) it would be valuable to model the spectral properties of real "defective" structures as well. We believe that the CCT approach could be effectively employed in order to provide Raman characteristics of such structures. With a model nanotube structure of significant length (20-units or even more) and possessing a certain amount of defects in hand it is possible to design both nondefective and defective fragments that will be used for the transfer. We presume that defective fragments need to be longer than non-defective fragments $(2 \times)$ in order to suppress the rim effect. Nevertheless, the precise methodology, as well as the quality of CCT predicted spectra in comparison with spectra modelled with plane-wave codes, has to be studied closely in some future work. Finally, we observed that spectra obtained by the CCT using a library of 4-unit fragments could sometimes also suffer from an artificial band splitting arising from rim effects. Thus, utilization of larger fragments (6-units) would be beneficial.

\section{Acknowledgements}

The financial support from IR-Graph (PL-TWIII/4/2016) project and the Faculty of Chemistry, University of Opole (Grant 8/WCH/2013-S) are acknowledged. The Czech Science Foundation (16-00270S) is also acknowledged. Access to computing and storage facilities owned by parties and projects contributing to the National Grid Infrastructure MetaCentrum, provided under the program "Projects of Large Infrastructure for Research, Development, and Innovations" (LM2010005), is greatly appreciated, as well as access to the CERIT-SC computing and storage facilities provided under the program Center CERIT Scientific Cloud, part of the Operational Program Research and Development for Innovations, reg. no. CZ. 1.05/3.2.00/08.0144. Michał Stachów was a recipient of a $\mathrm{PhD}$ fellowship from a project funded by the European Social Fund 'Uniwersytecki Program Stypendialny 2014-2015'. The Supercomputing and Networking Center ACK CYFRONET AGH in Krakow (grant MniSW/SGI3700/Uopolski/061/2008 and PL-GRID) and the Supercomputing and Networking Center in Wrocław are also acknowledged. 


\section{Notes and references}

1 S. Iijima, Nature, 1991, 354, 56-58.

2 A. Iijima and T. Ichihashi, Nature, 1993, 363, 603-605.

3 Y. Matsuda, J. Tahir-Kheli and W. A. Goddard, J. Phys. Chem. Lett., 2010, 1, 2946-2950.

4 R. Saito, M. S. Dresselhaus and G. Dresselhaus, Physical Properties of Carbon Nanotubes, Imperial College Press, London, 1998.

5 Z. Chen, D.-e. Jiang, X. Lu, H. F. Bettinger, S. Dai, P. v. R. Schleyer and K. N. Houk, Org. Lett., 2007, 9, 5449-5452.

6 H. W. Kroto, J. R. Heath, S. C. O'Brien, R. F. Curl and R. E. Smalley, Nature, 1985, 318, 162-163.

7 K. S. Novoselov, A. K. Geim, S. V. Morozov, D. Jiang, Y. Zhang, S. V. Dubonos, I. V. Grigorieva and A. A. Firsov, Science, 2004, 306, 666-669.

8 Y. F. Chan, H. Y. Peng, Z. K. Tang and N. Wang, Chem. Phys. Lett., 2003, 369, 541-548.

9 R. Saito, T. Takeya, T. Kimura, G. Dresselhaus and M. S. Dresselhaus, Phys. Rev. B: Condens. Matter Mater. Phys., 1999, 59, 2388-2392.

10 H. Kuzmany, W. Plank, M. Hulman, C. Kramberger, A. Gruneis, T. Pichler, H. Peterlik, H. Kataura and Y. Achiba, Eur. Phys. J. B, 2001, 22, 307-320.

11 A. Jorio, R. Saito, J. H. Hafner, C. M. Lieber, M. Hunter, T. McClure, G. Dresselhaus and M. S. Dresselhaus, Phys. Rev. Lett., 2001, 86, 1118-1121.

12 C. Qin and L. M. Peng, Phys. Rev. B: Condens. Matter Mater. Phys., 2002, 65, 1554311-1554317.

13 R. B. Weisman and S. M. Bachilo, Nano Lett., 2003, 3, 1235-1238.

14 G. Sun, J. Kürti, M. Kertesz and R. H. Baughman, J. Phys. Chem. B, 2003, 107, 6924-6931.

15 X. Zhao, Y. Liu, S. Inoue, T. Suzuki, R. O. Jones and Y. Ando, Phys. Rev. Lett., 2004, 92, 125502.

16 J. Maultzsch, H. Telg, S. Reich and C. Thomsen, Phys. Rev. B: Condens. Matter Mater. Phys., 2005, 72, 233403.

17 M. R. Mohammadizadeh, Physica E, 2006, 31, 31-37.

18 M. Aydin and D. L. Akins, Vib. Spectrosc., 2010, 53, 163-172. 19 N. Wang, G. D. Li and Z. K. Tang, Chem. Phys. Lett., 2001, 339, 47-52.

20 T. Kyotani, B. K. Pradhan and A. Tomita, Bull. Chem. Soc. Jpn., 1999, 72, 1957-1970.

21 L. Ci, Z. Zhou, D. Tang, X. Yan, Y. Liang, D. Liu, H. Yuan, W. Zhou, G. Wang and S. Xie, Chem. Vap. Deposition, 2003, 9, 119-121.

22 C. Kamal and A. Chakrabarti, Phys. Rev. B: Condens. Matter Mater. Phys., 2007, 76, 075113.

23 Y. F. Hsiou, Y. J. Yang, L. Stobiński, W. Kuo and C. D. Chen, Appl. Phys. Lett., 2004, 84, 984-986.

24 C.-H. Chen, W.-J. Liou, H.-M. Lin, S.-H. Wu, A. Mikołajczuk, L. Stobiński, A. Borodzinski, P. Kdzierzawski and K. Kurzydlowski, Phys. Status Solidi A, 2010, 207, 1160-1165. 25 X. Pan and X. Bao, Acc. Chem. Res., 2011, 44, 553-562.

26 A. Chutia, I. Hamada and M. Tokuyama, Chem. Phys. Lett., 2012, 550, 118-124.
27 A. Alexiadis and S. Kassinos, Chem. Eng. Sci., 2008, 63, 2047-2056.

28 F. Zhu and K. Schulten, Biophys. J., 2003, 85, 236-244.

29 J. Hu, T. W. Odom and C. M. Lieber, Acc. Chem. Res., 1999, 32, 435-445.

30 P. Okrasiński, Z. Latajka and C. Hättig, J. Phys. Chem. C, 2014, 118, 4483-4488.

31 K. N. Houk, P. S. Lee and M. Nendel, J. Org. Chem., 2001, 66, 5517-5521.

32 R. W. Lof, M. A. Van Veenendaal, B. Koopmans, H. T. Jonkman and G. A. Sawatzky, Phys. Rev. Lett., 1992, 68, 3924-3927.

33 X. Lu and Z. Chen, Chem. Rev., 2005, 105, 3643-3696.

34 T. Kupka, M. Stachów, E. Chełmecka, K. Pasterny and L. Stobiński, Synth. Met., 2012, 162, 573-583.

35 T. Kupka, M. Stachów, M. Nieradka and L. Stobiński, Magn. Reson. Chem., 2011, 49, 549-557.

36 T. Kupka, M. Stachów, E. Chełmecka, K. Pasterny, M. Stobińska, L. Stobiński and J. Kaminský, J. Chem. Theory Comput., 2013, 9, 4275-4286.

37 J.-i. Aihara, J. Phys. Chem. A, 1999, 103, 7487-7495.

38 R. G. Parr and Z. Zhou, Acc. Chem. Res., 1993, 26, 256-258.

39 U. Girreser, D. Giuffrida, F. H. Kohnke, J. P. Matthias, D. Philp and J. F. Stoddart, Pure Appl. Chem., 1993, 65, 119-125.

40 E. S. Kadantsev, M. J. Stott and A. Rubio, J. Chem. Phys., 2006, 124, 134901-134911.

41 Y. Yamakita, J. Kimura and K. Ohno, J. Chem. Phys., 2007, 126, 064904.

42 J. E. Anthony, Angew. Chem., Int. Ed., 2008, 47, 452-483.

43 R. Firouzi and M. Zahedi, THEOCHEM, 2008, 862, 7-15.

44 R. Mondal, C. Tonshoff, D. Khon, D. C. Neckers and H. F. Bettinger, J. Am. Chem. Soc., 2009, 131, 14281-14289.

45 Z. Qu, D. Zhang, C. Liu and Y. Jiang, J. Phys. Chem. A, 2009, 113, 7909-7914.

46 K. Tahara and Y. Tobe, Chem. Rev., 2006, 106, 5274-5290.

47 R. Gleiter, B. Esser and S. C. Kornmayer, Acc. Chem. Res., 2009, 42, 1108-1116.

48 E. Heilbronner, Helv. Chim. Acta, 1954, 37, 921-935.

49 R. Ghafouri and F. Ektefa, Struct. Chem., 2015, 26, 507-515. 50 J. Zhao, C. Jiang, Y. Fan, M. Burghard, T. Basché and A. Mews, Nano Lett., 2002, 2, 823-826.

51 The SDBS Spectral Database for Organic Compounds in AIST, http://sdbs.db.aist.go.jp, (accessed November 2012).

52 A. Jorio, C. Fantini, M. A. Pimenta, R. B. Capaz, G. G. Samsonidze, G. Dresselhaus, M. S. Dresselhaus, J. Jiang, N. Kobayashi, A. Grüneis and R. Saito, Phys. Rev. B: Condens. Matter Mater. Phys., 2004, 71, 075401-075411.

53 A. Jorio, A. P. Santos, H. B. Ribeiro, C. Fantini, M. Souza, J. P. M. Vieira, C. A. Furtado, J. Jiang, R. Saito, L. Balzano, D. E. Resasco and M. A. Pimenta, Phys. Rev. B: Condens. Matter Mater. Phys., 2005, 72, 075201-075205.

54 J. Kürti, H. Kuzmany, B. Burger, M. Hulman, J. Winter and G. Kresse, Synth. Met., 1999, 103, 2508-2509.

55 M. S. Dresselhaus, G. Dresselhaus, R. Saito and A. Jorio, Phys. Rep., 2005, 409, 47-99. 
56 M. S. Dresselhaus, G. Dresselhaus and A. Jorio, J. Phys. Chem. C, 2007, 111, 17887-17893.

57 M. S. Dresselhaus, G. Dresselhaus, R. Saito and A. Jorio, in Contemporary Concepts of Condensed Matter Science, ed. S. Saito and A. Zettl, Elsevier, 2008, vol. 3, pp. 83-108.

58 M. S. Dresselhaus and P. C. Eklund, Adv. Phys., 2000, 49, 705-814.

59 S. M. Bachilo, M. S. Strano, C. Kittrell, R. H. Hauge, R. E. Smalley and R. B. Weisman, Science, 2002, 298, 2361-2366.

60 M. S. Strano, M. Zheng, A. Jagota, G. B. Onoa, D. A. Heller, P. W. Barone and M. L. Usrey, Nano Lett., 2004, 4, 543-550.

61 M. S. Strano, S. K. Doorn, E. H. Haroz, C. Kittrell, R. H. Hauge and R. E. Smalley, Nano Lett., 2003, 3, 1091-1096.

62 T. Chang, Acta Mech. Sin., 2007, 23, 159-162.

63 M. Aydin, Vib. Spectrosc., 2013, 66, 30-42.

64 M. Aydin and D. Akins, in Nanotechnology and Nanomaterials. Electronic Properties of Carbon Nanotubes, ed. J. M. Marulanda, InTech, 2011.

65 A. Jorio, A. G. Souza Filho, G. Dresselhaus, M. S. Dresselhaus, A. K. Swan, M. S. Unlu, B. B. Goldberg, M. A. Pimenta, J. H. Hafner, C. M. Lieber and R. Saito, Mater. Res. Soc. Symp. Proc., 2002, 706, Z6.19.11.

66 M. A. Pimenta, A. Marucci, S. A. Empedocles, M. G. Bawendi, E. B. Hanlon, A. M. Rao, P. C. Eklund, R. E. Smalley, G. Dresselhaus and M. S. Dresselhaus, Phys. Rev. B: Condens. Matter Mater. Phys., 1998, 58, R16016-R16019.

67 S. D. M. Brown, A. Jorio, P. Corio, M. S. Dresselhaus, G. Dresselhaus, R. Saito and K. Kneipp, Phys. Rev. B: Condens. Matter Mater. Phys., 2001, 63, 155414-155418.

68 M. Jankowska, T. Kupka, L. Stobiński and J. Kaminský, J. Mol. Graphics Modell., 2015, 55, 105-114.

69 T. Kar, S. Scheiner and A. K. Roy, J. Phys. Chem. C, 2012, 116, 25401-25406.

70 S. Kar, S. Scheiner, A. K. Roy and H. F. Bettinger, J. Phys. Chem. C, 2012, 116, 26072-26083.

71 J. Beheshtian, A. A. Peyghan and Z. Bagheri, J. Mol. Model., 2012, 19, 391-396.

72 E. Zurek and J. Autschbach, J. Am. Chem. Soc., 2004, 126, 13079-13088.

73 E. Zurek, C. J. Pickard, B. Walczak and J. Autschbach, J. Phys. Chem. A, 2006, 110, 11995-12004.

74 E. Zurek and J. Autschbach, Int. J. Quantum Chem., 2009, 109, 3343-3367.

75 V. N. Popov, L. Henrard and P. Lambin, Phys. Rev. B: Condens. Matter Mater. Phys., 2005, 72, 035436.

76 V. N. Popov and P. Lambin, Phys. Status Solidi B, 2009, 246, 2602-2605.

77 W. A. Saidi and P. Norman, Carbon, 2014, 67, 17-26.

78 W. A. Saidi, J. Phys. Chem. A, 2014, 118, 7235-7241.

79 W. A. Saidi, J. Phys. Chem. C, 2013, 117, 9864-9871.

80 T. Kupka, E. Chełmecka, K. Pasterny, M. Stachów and L. Stobiński, Magn. Reson. Chem., 2012, 50, 142-151.

81 E. Chełmecka, K. Pasterny, T. Kupka and L. Stobinski, J. Mol. Model., 2012, 18, 1463-1472.
82 E. Chełmecka, K. Pasterny, T. Kupka and L. Stobiński, J. Mol. Model., 2012, 18, 2241-2246.

83 B. Esser, F. Rominger and R. Gleiter, J. Am. Chem. Soc., 2008, 130, 6716-6717.

84 B. Esser, A. Bandyopadhyay, F. Rominger and R. Gleiter, Chem. - Eur. J., 2009, 15, 3368-3379.

85 J. B. Foresman and A. Frisch, Exploring Chemistry with Electronic Structure Methods, Ed., Gaussian Inc, Pittsburg, PA, 2nd edn, 1996.

86 W. J. Hehre, L. Radom, P. V. R. Schleyer and J. A. Pople, $A b$ Initio Molecular Orbital Theory, Wiley, New York, 1986.

87 A. P. Scott and L. Radom, J. Phys. Chem., 1996, 100, 16502-16513.

88 A. Buczek, T. Kupka and M. A. Broda, J. Mol. Model., 2011, 17, 2029-2040.

89 N. A. Besley, J. J. Titman and M. D. Wright, J. Am. Chem. Soc., 2005, 127, 17948-17953.

90 S. Okubo, T. Okazaki, K. Hirose-Takai, K. Suenaga, S. Okada, S. Bandow and S. Iijima, J. Am. Chem. Soc., 2010, 132, 15252-15258.

91 M. J. Frisch, G. W. Trucks, H. B. Schlegel, G. E. Scuseria, M. A. Robb, J. R. Cheeseman, G. Scalmani, V. Barone, B. Mennucci, G. A. Petersson, H. Nakatsuji, M. Caricato, X. Li, H. P. Hratchian, A. F. Izmaylov, J. Bloino, G. Zheng, J. L. Sonnenberg, M. Hada, M. Ehara, K. Toyota, R. Fukuda, J. Hasegawa, M. Ishida, T. Nakajima, Y. Honda, O. Kitao, H. Nakai, T. Vreven, J. A. Montgomery Jr, J. E. Peralta, F. Ogliaro, M. J. Bearpark, J. Heyd, E. N. Brothers, K. N. Kudin, V. N. Staroverov, R. Kobayashi, J. Normand, K. Raghavachari, A. P. Rendell, J. C. Burant, S. S. Iyengar, J. Tomasi, M. Cossi, N. Rega, N. J. Millam, M. Klene, J. E. Knox, J. B. Cross, V. Bakken, C. Adamo, J. Jaramillo, R. Gomperts, R. E. Stratmann, O. Yazyev, A. J. Austin, R. Cammi, C. Pomelli, J. W. Ochterski, R. L. Martin, K. Morokuma, V. G. Zakrzewski, G. A. Voth, P. Salvador, J. J. Dannenberg, S. Dapprich, A. D. Daniels, A. Farkas, J. B. Foresman, J. V. Ortiz, J. Cioslowski and D. J. Fox, Rev. D.01, Gaussian, Inc, Wallingford CT, 2009.

92 A. D. Becke, J. Chem. Phys., 1993, 98, 5648-5652.

93 C. Lee, W. Yang and R. G. Parr, Phys. Rev. B: Condens. Matter Mater. Phys., 1988, 37, 785-789.

94 B. Miehlich, A. Savin, H. Stoll and H. Preuss, Chem. Phys. Lett., 1989, 157, 200-206.

95 P. Bouř, J. Sopková, L. Bednárová, P. Maloň and T. A. Keiderling, J. Comput. Chem., 1997, 18, 646-659 (Cartesian coordinate tensor transfer program, Petr Bouř, Institute of Organic Chemistry and Biochemistry Academy of Sciences of the Czech Republic, Prague, 1997-2011, http://hanicka.uochb.cas.cz/ bour/programs/F/cctn.f).

96 P. Danecek and P. Bouř, J. Comput. Chem., 2007, 28, 1617-1624.

97 S. Yamamoto, J. Kaminský and P. Bouř, Anal. Chem., 2012, 84, 2440-2451.

98 J. Kaminský, J. Kapitán, V. Baumruk, L. Bednárová and P. Bouř, J. Phys. Chem. A, 2009, 113, 3594-3601.

99 J. Kaminský, P. Bouř and J. Kubelka, J. Phys. Chem. A, 2011, 115, 30-34. 
100 S. Yamamoto, X. Li, K. Ruud and P. Bour, J. Chem. Theory Comput., 2012, 8, 977-985.

101 L. D. Barron, Molecular Light Scattering and Optical Activity, Cambridge University Press, 2nd edn, 2004.

102 T. Helgaker, W. Klopper, H. Koch and J. Noga, J. Chem. Phys., 1997, 106, 9639-9646.

103 D. Feller, J. Chem. Phys., 1993, 98, 7059-7071.

104 M. D. Segall, P. J. D. Lindan, M. J. Probert, C. J. Pickard, P. J. Hasnip, S. J. Clark and M. C. Payne, J. Phys.: Condens. Matter, 2002, 14, 2717-2744.
105 J. P. Perdew, K. Burke and M. Ernzerhof, Phys. Rev. Lett., 1996, 77, 3865-3868.

106 X. Gonze, Phys. Rev. B: Condens. Matter Mater. Phys., 1997, 55, 10337-10354.

107 Z. Zhou, M. Steigerwald, M. Hybertsen, L. Brus and R. A. Friesner, J. Am. Chem. Soc., 2004, 126, 3597-3607.

108 H. M. Lawler, D. Areshkin, J. W. Mintmire and C. T. White, Phys. Rev. B: Condens. Matter Mater. Phys., 2005, 72, 233403.

109 A. Kasuya, Y. Sasaki, Y. Saito, K. Tohji and Y. Nishina, Phys. Rev. Lett., 1997, 78, 4434-4437. 